\title{
Quantitative comparison of different inhaled corticosteroids in the treatment of asthma in children aged 5-12
}

\author{
Haoxiang Zhu ${ }^{1}$, Qingshan Zheng ${ }^{1}$, Hongxia Liu ${ }^{1}$, and Lujin $\mathrm{Li}^{1}$ \\ ${ }^{1}$ Shanghai University of Traditional Chinese Medicine
}

May 5, 2021

\begin{abstract}
Objective: Inhaled corticosteroids (ICS) are recommended by the Global Initiative for Asthma for the treatment of steps 2-3 childhood asthma. However, the difference in efficacy between these different ICS drugs is not clear. The main purpose of this study was to compare the efficacy of different ICS drugs in the treatment of childhood asthma and to provide effective quantitative information for guiding their use. Methods: We searched PubMed and EMBASE for randomized controlled trials of ICS in the treatment of childhood asthma. Using forced expiratory volume in the first second $\left(F^{2} V_{1}\right)$ as the efficacy index, a time-course model of ICS drugs was constructed. Related influencing factors were also investigated. Important pharmacodynamic parameters, such as maximum efficacy and onset time of each ICS, were calculated to reflect their differences in efficacy characteristics. Results: A total of 6 studies involving 2237 children were analyzed, including five arms of BUD (456 subjects), three arms of CIC (876 subjects), two arms of FP (352 subjects), one arm of MF (197 subjects), and three arms of FF (356 subjects). Since the study was limited by the data collected, pharmacodynamic models could only be constructed for BUD and CIC. The results showed that there was no significant difference in the maximum efficacy between BUD and CIC, and that the $\mathrm{E}_{\max }$ values of the percentage change in $\mathrm{FEV}_{1}$ were 17.4 (95\% CI: 16.9, 17.9)\%. The $\mathrm{ET}_{50}$ of CIC and BUD was 1.23 (95\% CI: $0.76,1.70)$ weeks and 2.97 (95\% CI: 1.8, 4.14) weeks, respectively. Compared with the $95 \%$ confidence intervals of BUD and CIC, FP had the highest efficacy, MF had the lowest efficacy, and the efficacy of FF was comparable to that of BUD and CIC. Conclusion: In this study, the efficacy of five ICS drugs was quantitatively compared, providing necessary information for the implementation of medication guidelines for steps 2-3 asthma in children.
\end{abstract}

\section{Hosted file}

Manuscript.pdf available at https://authorea.com/users/411952/articles/520816-quantitativecomparison-of-different-inhaled-corticosteroids-in-the-treatment-of-asthma-in-childrenaged-5-12

\section{Hosted file}

figures.pdf available at https://authorea.com/users/411952/articles/520816-quantitativecomparison-of-different-inhaled-corticosteroids-in-the-treatment-of-asthma-in-childrenaged-5-12

\section{Hosted file}

table1.pdf available at https://authorea.com/users/411952/articles/520816-quantitativecomparison-of-different-inhaled-corticosteroids-in-the-treatment-of-asthma-in-childrenaged-5-12

\section{Hosted file}


table2-3.pdf available at https://authorea.com/users/411952/articles/520816-quantitativecomparison-of-different-inhaled-corticosteroids-in-the-treatment-of-asthma-in-childrenaged-5-12 